Localizador: 19008 doi: 10.35366/93982

\title{
Infección gonocócica diseminada: otra gran simuladora
}

\author{
Disseminated gonococcal infection: another great simulator
}
Andrés Label,* Luciana L Tirelli, ${ }^{\ddagger}$ Paula C Luna, ${ }^{\S}$ Verónica L Llorca, ${ }^{\S}$ Juan J Solé, ${ }^{\S}$ Félix A Vigovich," Margarita Larraldeף

Palabras clave: Neisseria gonorrhoeae, infección gonocócica diseminada, pápulaspústulas, fiebre.

Keywords: Neisseria gonorrhoeae, disseminated gonococcal infection, papulespustules, fever.

* Residente de Dermatología. * Fellow de Dermatología.

$\S$ Médico de Staff del Servicio de Dermatología.

" Médico de Staff del Servicio de Anatomía Patológica.

" Jefa del Servicio de

Dermatología.

Servicio de Dermatología del Hospital Alemán. Ciudad Autónoma de Buenos Aires, Argentina.

Conflicto de intereses: Ninguno.

Recibido: 12/Febrero/2019.

Aceptado: 30/Julio/2019

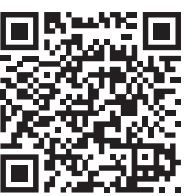

\section{Resumen}

La gonorrea es una enfermedad de transmisión sexual, que en la mayoría de los casos genera afectación mucosa. En un bajo porcentaje, genera un cuadro que se conoce como infección gonocócica diseminada. Su dificultad al momento del diagnóstico se debe a la baja sensibilidad de los métodos complementarios y a su camaleónica presentación clínica. Puede confundirse con distintas entidades, como sífilis, VIH, parvovirus B19 y enfermedades autoinflamatorias. Es importante tener en cuenta a la hora de realizar el tratamiento utilizar un esquema doble, con cobertura de gérmenes intracelulares como Chlamydia, ya que hasta en un 30\% de los casos existe la confección por ambos gérmenes. Se decide presentar un caso clínico, que nos presentó un desafío diagnóstico por su heterogeneidad clínica, planteándonos múltiples diagnósticos diferenciales hasta arribar al diagnóstico de certeza. Por este motivo, creemos que es importante considerar a la infección gonocócica diseminada como un diagnóstico probable frente a casos clínicos de características similares.

\section{ABSTRACT}

Conorrhea is a sexually transmitted disease, which in most cases causes mucosal involvement. In a low percentage, it generates a picture known as disseminated gonococcal infection. Its difficulty at the time of diagnosis is due to the low sensitivity of the complementary methods and its chameleonic clinical presentation. It can be confused with different entities, such as syphilis, HIV, parvovirus B19 and autoinflammatory diseases. It is important to take into account when carrying out the treatment use a double scheme, with coverage of intracellular germs such as Chlamydia since up to $30 \%$ of cases there is preparation for both germs. It was decided to present a clinical case, which presented a diagnostic challenge due to its clinical heterogeneity, posing multiple differential diagnoses until arriving at the diagnosis of certainty. For this reason, we believe that it is important to consider disseminated gonococcal infection as a probable diagnosis in the face of clinical cases with similar characteristics.

40 años y mujeres, debido a la presentación subclínica de la infección genital.

Clínicamente se manifiesta como una tríada de rash, tenosinovitis y artritis/artralgias, o su variante, como artritis séptica sin compromiso cutáneo.

\section{PRESENTACIÓN DEL CASO} agente etiológico responsable es la Neisseria gonorrhoeae, un diplococo intracelular aeróbico Gram negativo, el cual clásicamente afecta superficies mucosas y se caracteriza por cervicitis, uretritis y enfermedad pélvica inflamatoria.

Raramente puede diseminarse por vía hemática dando lugar a la infección gonocócica diseminada (IGD). Esta complicación muy poco frecuente, presenta como factores de riesgo a los pacientes sexualmente activos, menores de
Paciente masculino de 27 años, sin antecea nuestro servicio por un cuadro de fiebre y exantema pápulo-pustuloso generalizado de 15 días de evolución. Al examen físico, el paciente presentaba buen estado general, se constataron múltiples lesiones pápulo-pustulosas de coloración violácea, que asentaban sobre una base eritematosa de límites difusos, localizadas en dentes patológicos de relevancia, consultó 
tronco, miembros superiores e inferiores (Figuras 1 y 2). Una de ellas, a nivel del quinto dedo de mano izquierda, de aspecto hemorrágico (Figura 3).

Además, presentaba amígdalas hipertróficas con exudado blanquecino bilateral, sin adenomegalias. El paciente negó haber presentado secreción uretral purulenta, pero refirió haber tenido relaciones sexuales ocasionales no protegidas y consumo de antiinflamatorios no esteroideos (AINEs) desde el inicio de los síntomas. Se realizaron estudios complementarios, donde se constató leucocitosis de 23.800 (82\% neutrófilos), virus de la inmunodeficiencia humana (VIH) negativo, venereal disease research laboratory (VDRL) no reactiva, serología para parvovirus B19 negativa y exudado de fauces que informó flora habitual. Como estudios de imágenes se solicitó una ecografía abdominal y una tomografía de tórax, en las cuales no se evidenciaron hallazgos patológicos. Se realizaron hemocultivos x 2 y se realizó una biopsia de piel, a fin de descartar dermatosis neutrofílica en primera instancia, de una pústula a nivel del hombro izquierdo (Figura 4); la cual

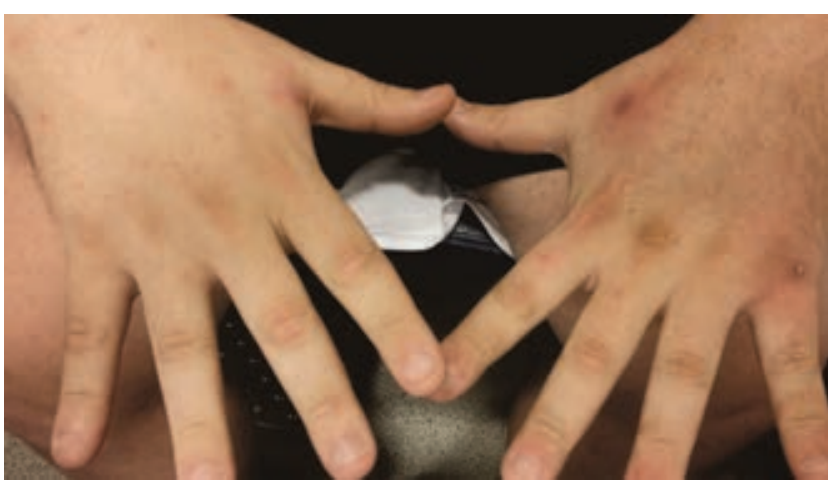

Figura 1: Lesiones pápulo-pustulosas que asientan sobre base eritematosa en dorso de ambas manos.

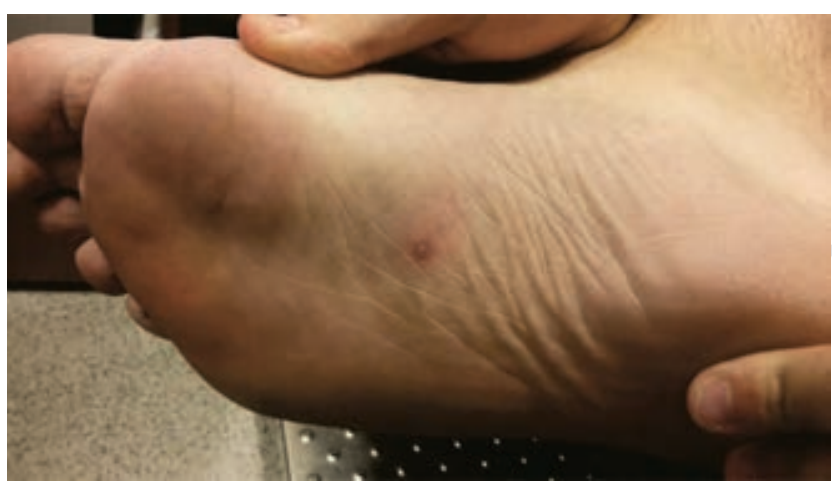

Figura 2: Lesión pustulosa en planta de pie derecho.

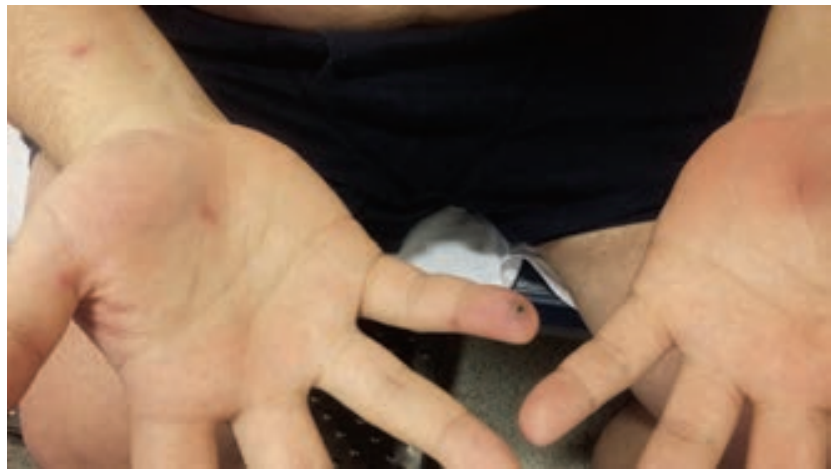

Figura 3: Lesión hemorrágica en el quinto dedo de mano derecha.

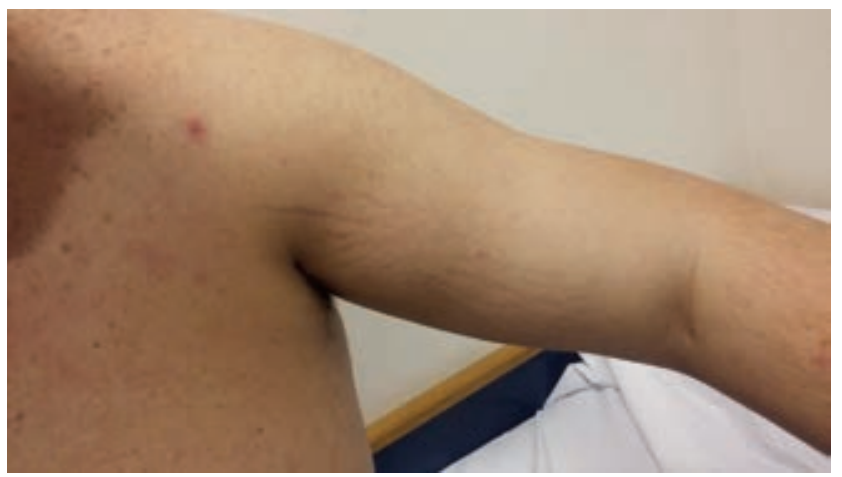

Figura 4: Pústula en hombro izquierdo donde se realizó la biopsia.

informó una dermatosis que combinaba hallazgos de pústulas subcorneas y vasculitis leucocitoclásica (Figuras 5 a 7). A las 48 horas de la toma de la biopsia se recibió informe de los hemocultivos con rescate de Neisseria gonorrhoeae en ambos frascos; por lo que se interpretó el cuadro como una gonococemia diseminada. En forma conjunta con el Servicio de Infectología se decidió comenzar el tratamiento con ceftriaxona EV 2 g/día durante 10 días asociado a 1 g de azitromicina vía oral en monodosis; evolucionando de manera favorable.

\section{DISCUSIÓN}

La Neisseria gonorrhoeae es un diplococo Gram negativo que suele afectar las superficies mucosas, tales como tracto genital, rectal o faríngeo, ${ }^{1}$ siendo la cervicitis y la enfermedad pélvica inflamatoria la forma de manifestación más frecuente en mujeres y la uretritis y epididimitis en hombres. $^{2}$

La infección gonocócica diseminada (IGD) es el producto de la diseminación hemática de Neisseria gonorrhoeae, ${ }^{3}$ 


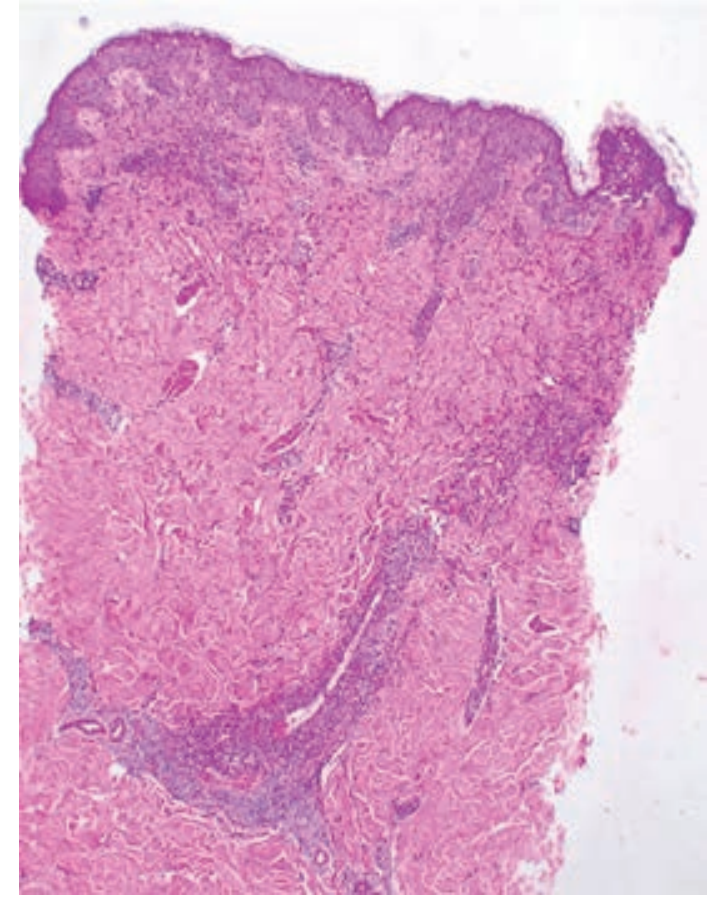

Figura 5: En la vista panorámica se observa leve hiperplasia epidérmica y en dermis un infiltrado inflamatorio angiocéntrico.

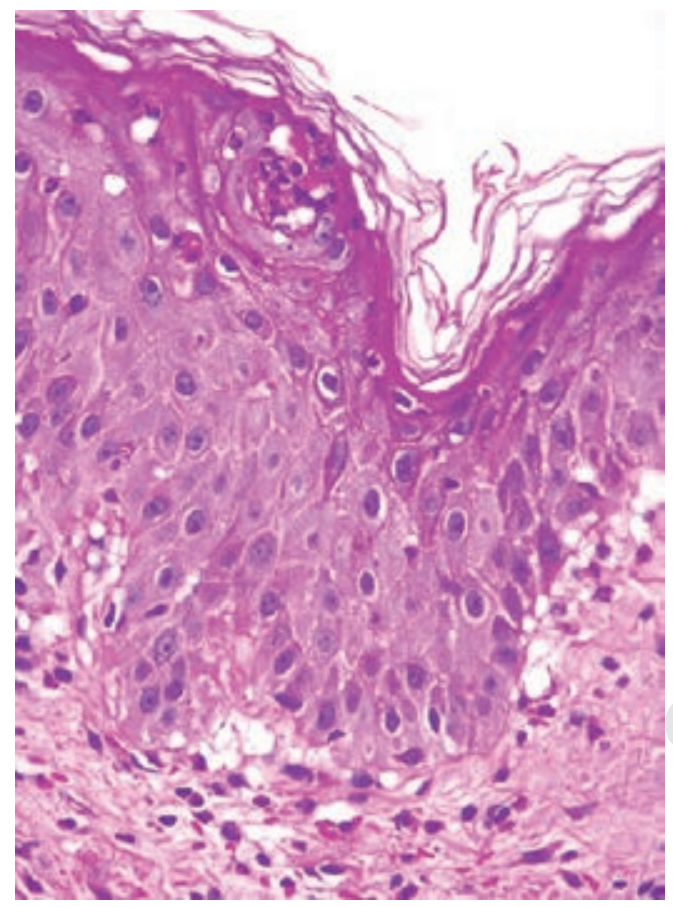

Figura 6: A nivel de epidermis superficial se ve espongiosis y microabscesos. Extravasación de glóbulos rojos en dermis.

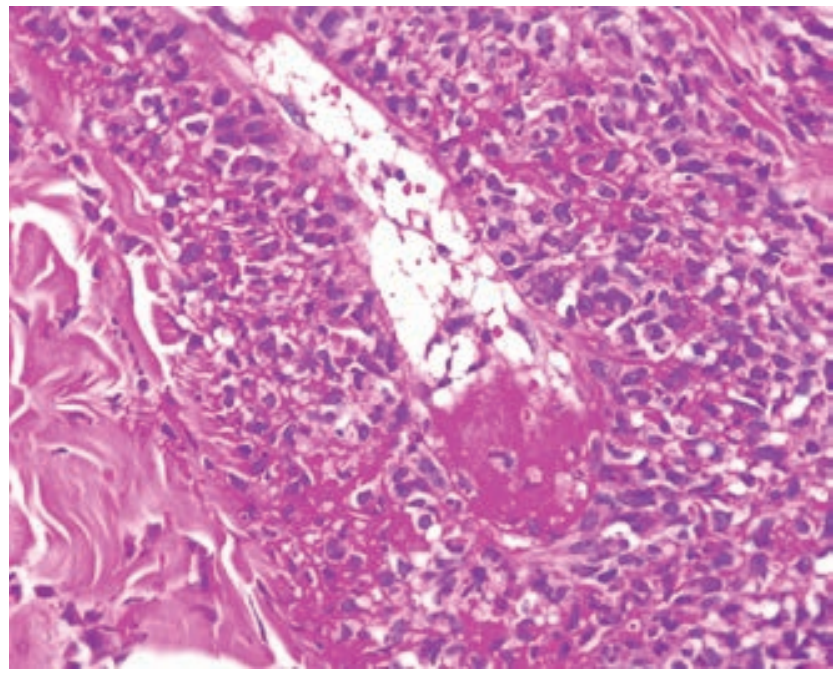

Figura 7: Vaso de dermis reticular con compromiso parietal y depósitos de fibrina.

que suele presentarse de dos a tres semanas posteriores a la primoinfección. ${ }^{4}$

Presenta una incidencia de 0.5 a 3\% de todos los pacientes con gonorrea. ${ }^{1-9}$

Se postula que la incidencia de la IGD sería en realidad mayor, pero su subdiagnóstico se correspondería a distintas causas, como la presentación clínica inespecífica o asintomática de la infección primaria ${ }^{5}$ y la baja sensibilidad de los métodos complementarios, entre los que se destaca la variación de la sensibilidad de los hemocultivos según el momento en el que se realice el diagnóstico, siendo en estadios más tempranos la sensibilidad cercana al 50\% y disminuye la misma a medida que transcurre el tiempo de evolución. ${ }^{2,5,6}$ Además, el anticoagulante (polianetol sulfonato de sodio) utilizado en los frascos de hemocultivo, puede actuar como inhibidor de este grupo de bacterias. ${ }^{2}$

En cuanto a la patogénesis de la IGD depende tanto de factores predisponentes del huésped como de la bacteria. Dentro de los primeros se pueden mencionar la infección mucosa asintomática, menstruación reciente en sexo femenino, embarazo, múltiples parejas sexuales, bajo nivel socioeconómico, VIH positivo, déficit de complemento (congénito o adquirido), lupus eritematoso sistémico (LES), entre otros. ${ }^{1-4,7}$

Asociado a éstos, se agregan ciertas características de la bacteria per se, como ser el serotipo proteína 1A, el lípido A, o aquéllas que carecen de la proteína II, entre otras, que favorecen a generar una infección diseminada, ya que generan una menor respuesta inflamatoria en el huésped y por ende cursan primoinfecciones oligosintomáticas. ${ }^{4}$ 
Respecto a su presentación clínica, se pueden dividir en dos grandes grupos: la forma de presentación clásica que se caracteriza por la tríada de exantema, tenosinovitis, y poliartralgias (sin artritis purulenta), también conocido como síndrome artritis-dermatitis, ${ }^{2}$ habitualmente acompañado de síntomas generales como fiebre, escalofríos y astenia.

El compromiso cutáneo es extremadamente polimorfo, pueden observarse una gran variedad de lesiones elementales, como máculas, pápulo-pústulas o vesículas tensas sobre una base hemorrágica comprometiendo principalmente las extremidades. Otras lesiones cutáneas descritas pueden incluir abscesos, celulitis, petequias, púrpura, fascitis necrosante y vasculitis. ${ }^{1}$ La afección articular en esta variante se manifiesta como poliartralgias migratorias y asimétricas.

El segundo grupo se suele presentar como artritis séptica, por lo general sin compromiso cutáneo. ${ }^{2}$

Tal como se mencionó anteriormente, a fin de arribar a un diagnóstico definitivo se aconseja obtener distintos tipos de muestra para el rescate del microorganismo, el cual confirma el diagnóstico.

Se sugiere tomar cultivos de mucosa urogenital, rectal y faríngea. En caso de disponer de técnica de polymerase chain reaction (PCR) validada, se aconseja la realización de la misma sobre las muestras obtenidas (orina en hombres e hisopado vaginal en mujeres), ya que es el estudio con mejor rédito diagnóstico. En caso de no contar con este método, se sugiere la realización del cultivo de las muestras (hisopado uretral y cervical) procesado en medio de Thayer-Martin..$^{1,2}$

Asimismo, se recomienda la realización de hemocultivos x 2 y cultivo de líquido sinovial si correspondiera. En el caso de obtener rescate bacteriológico, hay que realizar antibiograma.

Si bien existe evidencia de que $N$. gonorrhoeae invade el tejido cutáneo, tanto el cultivo de piel como la biopsia de las lesiones tienen bajo rédito diagnóstico, ${ }^{2}$ pero son de utilidad para descartar diagnósticos diferenciales.

Por lo regular, se requiere más de un método diagnóstico para confirmar la infección, ya que ninguno es 100\% sensible.

Sobre los diagnósticos diferenciales se debe tener en cuenta el grupo de enfermedades de transmisión sexual, como sífilis, VIH, parvovirus B19, LES, enfermedades neutrofílicas, endocarditis con embolizaciones sépticas y eritema multiforme, entre otras entidades.
En relación con el tratamiento, las cefalosporinas de tercera generación constituyen los antibióticos de elección para este germen (ceftriaxona $1 \mathrm{~g} /$ día intramuscular o endovenoso de siete a 14 días) asociado con una monodosis de azitromicina $1 \mathrm{~g}$ (para cubrir también Chlamydia trachomatis, ya que hasta en un 30\% de los casos estas dos ITS coexisten en un mismo individuo). ${ }^{2,5}$

Asimismo, se sugiere realizar tratamiento a las parejas sexuales y todos los pacientes deben ser testeados para otras infecciones de transmisión sexual como VIH y sífilis.

Entre las complicaciones severas de la IGD pueden mencionarse la endocarditis, meningitis, abscesos hepáticos y osteomielitis, todas estas relacionadas a un pronóstico sombrío.

\section{CONCLUSIONES}

El objetivo de presentar este caso, radica en comunicar una patología infrecuente (la primera en nuestro centro), la cual predomina en pacientes jóvenes, sexualmente activos, que en muchos casos es subdiagnosticada debido a su presentación clínica variable, y la falta de estudios complementarios con alta sensibilidad, pudiendo evolucionar a cuadros de mayor severidad con compromiso para la vida del paciente. Hay que considerarlo como diagnóstico diferencial del grupo de enfermedades neutrofílicas (como síndrome de Sweet).

Se debe recalcar la importancia de sospechar IGD en pacientes sexualmente activos, con dolor articular no atribuible a otra causa (por ejemplo traumatismos) y lesiones cutáneas.

Además, es importante destacar la importancia de la sospecha clínica y el tratamiento oportuno, tanto para Neisseria gonorrhoeae como para Chlamydia trachomatis, ya que en un alto porcentaje coexisten ambas infecciones $y$, por último, aprovechar la oportunidad para realizar el testeo de otras enfermedades de transmisión sexual.

\author{
Correspondencia: \\ Dr. Andrés Label \\ Hospital Alemán. \\ Av. Pueyrredón Núm. 1640, \\ CABA, Argentina. \\ Tel: 4827-7000 \\ E-mail: andreslabel@hotmail.com
}




\section{BIBLIOGRAFÍA}

1. Beatrous SV, Grisoli SB, Riahi RR, Matherne RJ, Matherne RJ. Cutaneous manifestations of disseminated gonococcemia. Dermatol Online J. 2017; 23 (1): pii: 13030/qt33b24006.

2. Burns JE, Graf EH. The brief case: disseminated Neisseria gonorrhoeae in an 18-year-old female. J Clin Microbiol. 2018; 56 (4). pii: e00932-17.

3. Rueda DA, Aballay L, Orbea L, Carrozza DA, Finocchietto $P$, Hernandez SB et al. Fitz-Hugh-Curtis syndrome caused by gonococcal infection in a patient with systemic lupus erythematous: a case report and literature review. Am J Case Rep. 2017; 18: 1396-1400.

4. Lee MH, Byun J, Jung M, Yang JJ, Park KH, Moon SY et al. Disseminated gonococcal infection presenting as bacteremia and liver abscesses in a healthy adult. Infect Chemother. 2015; 47 (1): 60-63.
5. Lohani S, Nazir S, Tachamo N, Patel N. Disseminated gonococcal infection: an unusual presentation. J Community Hosp Intern Med Perspect. 2016; 6 (3): 31841.

6. Hagiya $\mathrm{H}$, Onishi $\mathrm{N}$, Ebara $\mathrm{H}$, Hanayama $\mathrm{Y}$, Kokeguchi $\mathrm{S}$, Nose $\mathrm{M}$ et al. Disseminated gonococcal infection in an elderly Japanese man. Intern Med. 2013; 52 (23): 2669-2673.

7. Romiopoulos I, Pyrpasopoulou A, Varouktsi A, Simoulidou E, Kontopoulou K, Karantani E et al. A rare case of disseminated pyogenic gonococcal infection in an immunocompetent woman. Case Rep Infect Dis. 2016; 2016: 9629761.

8. Crew PE, Abara WE, McCulley L, Waldron PE, Kirkcaldy RD, Weston EJ et al. Disseminated gonococcal infections in patients receiving eculizumab: a case series. Clin Infect Dis. 2018. doi: 10.1093/cid/ciy958. [Epub ahead of print]

9. Bollea-Garlatti LA, Vaglio-Giors G, Guzzi-Maqueda M, Volonteri V, Galimberti R. Infección gonocócica diseminada. Dermatol Argent. 2013; 19 (4): 292-295. 